\title{
Randomly Amplified Polymorphic DNAs in the Cultivated Strawberry, Fragaria $\times$ ananassa
}

\author{
J.F. Hancock and P.A. Callow \\ Department of Horticulture, Michigan State University, East Lansing, MI 48824 \\ Douglas V. Shaw \\ Department of Pomology, University of California, Davis, CA 95616
}

Additional index words. molecular fingerprints, cultivar identification, strawberry breeding

\begin{abstract}
Eight strawberry cultivars or advanced selections from the Univ. of California, Davis, breeding program were screened for polymorphisms using the polymerase chain reaction (PCR) and 43 random 10 -base DNA primers. Over $60 \%$ of the primers screened resulted in replicable polymorphic banding patterns (amplification profiles), and a subset of ten primers that exhibited high levels of amplification profile polymorphism was used to identify each of the eight genotypes uniquely. There was also a significant product-moment correlation $(r=0.64, P<0.01)$ between number of shared amplification profile phenotypes and pairwise coefficient of coancestry. This technology shows high promise as a means of verifying the identity of cultivars and developing a genetic map of the octoploid cultivated strawberry.
\end{abstract}

Molecular markers are playing an increasingly important role in genetic studies of horticultural crops. Isozymes, restriction fragment length polymorphisms (RFLPs), and randomly amplified polymorphic DNAs (RAPDs) have a wide array of uses including genetic mapping, tagging genes of interest, pedigree verification, cultivar identification, and measuring levels of genetic diversity (O'Brien, 1990). Isozymes and RFLPs have been the most widely employed genetic markers, but interest in RAPDs is rapidly growing as they are often highly polymorphic and their identification requires no radioactivity (Grattapaglia et al, 1992).

Randomly amplified polymorphic DNA profiles represent base differences or chromosomal rearrangements that are uncovered after polymerase chain reaction (PCR) amplification using random oligonucleotide primers (Williams et al., 1990). Randomly amplified polymorphic DNA markers are generally expressed as dominant traits, because amplification of a product proceeds with the presence of a pair of sequences homologous to that of the primer on either one or both homologous chromosomes. Randomly amplified polymorphic DNAs have been used to distinguish genotypes of asparagus, beans, peas, peppers, watermelons (Weeden et al., 1992), broccoli, cauliflower (Hu and Quiros, 1991), lettuce (Paran et al., 1992), tomato (Klein-Lankhorst et al., 1991), and wheat (Vierling and Nguyen, 1992).

Isozymes have been used to characterize strawberry cultivars; however, only $60 \%$ of the genotypes from the Univ. of California breeding program could be distinguished using three enzyme systems (Arulsekar et al., 1981; Bringhurst et al., 1981). This lack of resolution limits the utility of allozymes in cultivar identification and breeding. In contrast, Davis (1993) has described high levels of RAPD diversity in the diploid $F$. vesca and Rowland (personal comment) has observed high levels of variation among octoploid $F$. x ananassa cultivars. We undertook this survey to determine if similar levels of RAPD diversity might also be found within a breeding population of $F$. ×ananassa.

Received for publication 21 June 1993. Accepted for publication 17 Dec. 1993. The cost of publishing this paper was defrayed in part by the payment of page charges. Under postal regulations, this paper therefore must be hereby marked advertisement solely to indicate this fact.

\section{Materials and Methods}

Eight cultivars or selections were chosen for study from the Univ. of California Strawberry Improvement Program (Table 1). These genotypes represent a highly related subset of the germplasm available in this program; many are siblings or parentoffspring pairs. A related sample of genotypes was chosen to challenge the resolution power of the molecular markers. Coefficients of coancestry estimated using SAS Procedure INBREED (SAS Institute, 1988) ranged from 0.113 to 0.386 for pairwise comparisons of these eight genotypes (Table 1), and several of the genotypes in this sample share a common parent or are related as offspring-parent.

Total cellular DNA was isolated from fully expanded leaves of greenhouse-grown plants using a modification of a CTAB procedure (Haghighi and Hancock, 1992). DNA was amplified in $25 \mu \mathrm{l}$ volumes using 10-base primers (from Operon Technologies, Alameda, Calif.). Reaction conditions were $1 \mathrm{ng} \cdot \mu^{-1}$ strawberry DNA, buffer (50 mм KCL, $10 \mathrm{~mm}$ Tris- $\mathrm{HCl} \mathrm{pH} 8.3$ ), $2.0 \mathrm{~mm}$ $\mathrm{MgCl}_{2}, 200$ um dATP, dCTP, dGTP, dTTP (Perkin Elmer), $0.2 \mu \mathrm{M}$ primer, and 0.026 units/ $\mu 1$ Taq DNA polymerase (Perkin Elmer). The thermo-cycle profile was preceded with an initial denaturation soak for $5 \mathrm{~min}$ at $94 \mathrm{C}$. DNA was amplified for 47 cycles in a Perkin Elmer thermal cycler programmed for $1 \mathrm{~min}$ at $94 \mathrm{C}, 1 \mathrm{~min}$ at 40C, and $2 \mathrm{~min}$ at $72 \mathrm{C}$, followed by a 5 -min soak at $72 \mathrm{C}$. The DNA fragments were run in $1.0 \%$ agarose gels and visualized by ethidium bromide staining.

\section{Results and Discussion}

The PCR conditions were optimized using a variety of reaction conditions. From an initial group of 43 primers, 28 (65\%) were useful in distinguishing among the eight genotypes; 11 of the remainder lacked polymorphism in this sample and four failed to produce amplification profiles. Of the 28 primers that produced polymorphic amplification product profiles, the ten with the greatest level of polymorphism were used to further evaluate the power of this technology for discriminating among genotypes and obtaining quantitative relationships.

Each primer yielded a wide array of strong and weak bands (Fig. 1, Table 2); only reproducible fragments with intense bands were scored in our comparisons. The different amplification profiles 
Table 1. Coefficients of coancestry (above diagonal) and the number of shared RAPD amplification profiles (below the diagonal) for eight strawberry clones and ten marker systems.

\begin{tabular}{lccccccrr}
\hline \hline & $75.121-101$ & $81.16-604$ & $83.25-2$ & $85.22-1$ & Capitola & Chandler & Douglas & Seascape \\
\hline $75.121-101$ & --- & 0.174 & 0.160 & 0.372 & 0.372 & 0.113 & 0.180 & 0.182 \\
$81.16-604$ & 0 & --- & 0.279 & 0.386 & 0.278 & 0.254 & 0.387 & 0.330 \\
$83.25-2$ & 1 & 1 & --- & 0.219 & 0.273 & 0.188 & 0.288 & 0.251 \\
$85.22-1$ & 3 & 2 & 3 & --- & 0.325 & 0.184 & 0.283 & 0.256 \\
Capitola & 6 & 1 & 2 & 2 & --- & 0.184 & 0.283 & 0.256 \\
Chandler & 0 & 2 & 2 & 1 & 0 & --- & 0.328 & 0.236 \\
Douglas & 0 & 4 & 3 & 2 & 0 & 5 & --- & 0.382 \\
Seascape & 1 & 3 & 4 & 3 & 1 & 5 & 5 & --- \\
\hline
\end{tabular}

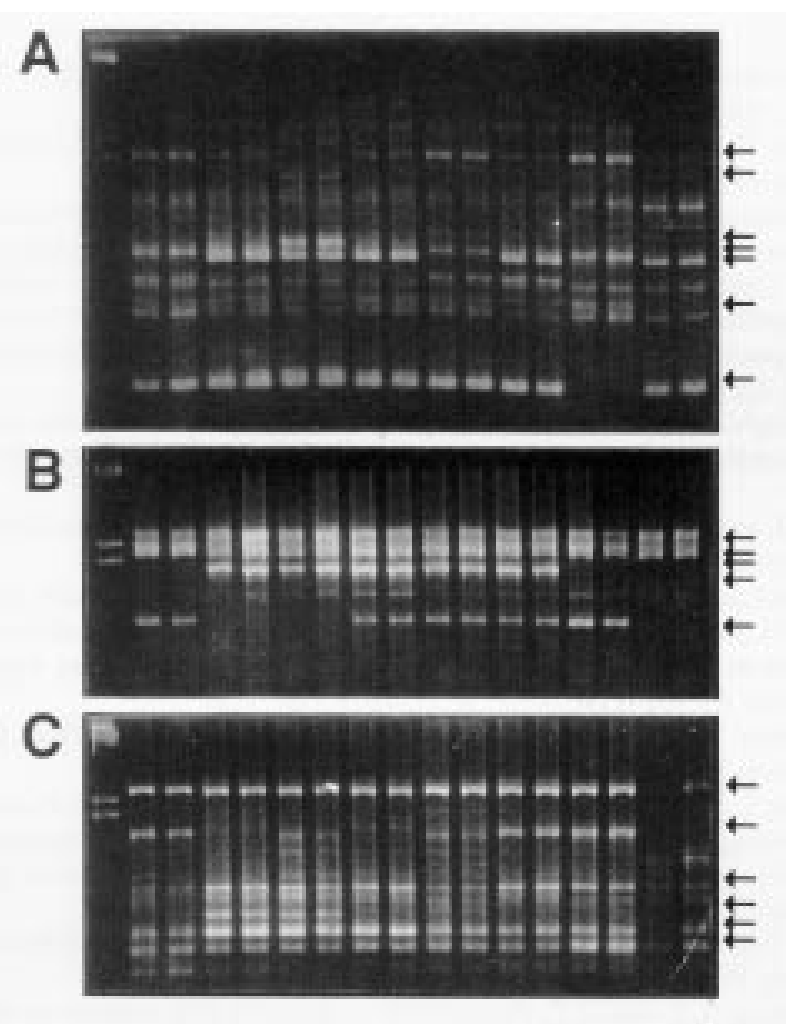

Fig. 1. DNA profiles generated by primers $\mathrm{C}$ (top), E (middle) and $\mathrm{G}$ (bottom). The lanes and their contents are: 1 (Size markers from HindIII digests of lambda DNA), 2-3 (Chandler), 4-5 (Capitola), 6-7 (75.121-101), 8-9 (85.22-1), 10-11 (Douglas), 12-13 (Seascape), 14-15(81.16-604), 16-17(83.25-2). The fragments used in the statistical analysis are marked by arrows.

were given an alpha-numeric designation, where a letter was used to represent each primer and a number to denote the different DNA patterns obtained with that primer (Table 3 ).

The cultivars and selections were readily distinguished by their DNA amplification profiles (Tables 2 and 3). For this subset of 10 primers, 28 of the 54 fragments identified were polymorphic. From two to six unique amplification profiles were found with each primer. All of the primers distinguished at least $50 \%$ of the genotypes in pairwise comparisons and some separated all but a few cultivars (Table 3). Amplification profiles from primerA (5'-CCGCATCTAC) differed in 26 of 28 pairwise genotypic comparisons, and profiles from primers $\mathrm{F}$ (5'-GGACCCAACC) and $\mathrm{H}$ (5'-AGCGCCGTCA) distinguished 25 of 28.

The number of shared amplification profiles ranged from 0 to 6 of 10 for all pairwise comparisons (Table 1). The productmoment correlation between the number of shared profiles and pairwise coefficient of coancestry was $r=0.64(P<0.01)$. Although the number of genotypes evaluated was rather small, this result suggests that these highly diverse markers may be a powerful tool for detecting patterns of relatedness in strawberry populations. Genetic similarities generated by selection from a common ancestral base, rather than coancestry, might be detected by appropriate comparisons within and among breeding populations adapted to differing production environments.

Many of the accessions here are close relatives, and are expected to share a large fraction of their genomes. However, the power of resolution even for these closely related items is exceptional. For example, Capitola and 85.22-1 share selection 75.121-101 as a common parent, but have different amplification profiles for 8 of the 10 primers listed in Table 3 . In addition, the two derivative genotypes differ from their common parent at 4 of 10

Table 2. Primers used and number of different DNA fragments and profiles observed among eight strawberry clones. There were 28 possible pairwise comparisons between each of the clones.

\begin{tabular}{|c|c|c|c|c|c|}
\hline \multirow[b]{2}{*}{ Primer } & \multirow[b]{2}{*}{ Sequence } & \multicolumn{2}{|c|}{$\begin{array}{l}\text { No. fragments } \\
\text { observed }\end{array}$} & \multirow{2}{*}{$\begin{array}{r}\text { No. DNA } \\
\text { profiles }\end{array}$} & \multirow{2}{*}{$\begin{array}{c}\text { No. distinct } \\
\text { pairwise } \\
\text { comparisons }\end{array}$} \\
\hline & & Total & Polymorphic & & \\
\hline A & CCG CAT CTA C & 7 & 5 & 6 & 26 \\
\hline B & GTC CCG ACG A & 3 & 1 & 2 & 15 \\
\hline $\mathrm{C}$ & TGG ACC GGT G & 7 & 6 & 4 & 22 \\
\hline $\mathrm{D}$ & GTT GCC AGC C & 4 & 1 & 3 & 19 \\
\hline $\mathrm{E}$ & ACC GCG AAG G & 5 & 2 & 4 & 21 \\
\hline $\mathrm{F}$ & GGA CCC AAC C & 9 & 5 & 5 & 25 \\
\hline $\mathrm{G}$ & GTC GCC GTC A & 6 & 2 & 4 & 22 \\
\hline $\mathrm{H}$ & AGC GCC ATT G & 4 & 2 & 5 & 25 \\
\hline I & GAG AGC CCA C & 4 & 2 & 3 & 20 \\
\hline $\mathrm{J}$ & AGA TGC AGC C & 5 & 2 & 3 & 17 \\
\hline
\end{tabular}


Table 3. Amplification profiles observed among the eight strawberry genotypes. A letter was used to represent each primer and a number to denote the different amplification profiles obtained with that primer.

\begin{tabular}{|c|c|c|c|c|c|c|c|c|c|c|}
\hline \multirow{2}{*}{$\frac{\text { Genotype }}{75.121-101}$} & \multicolumn{10}{|c|}{ Amplification profile } \\
\hline & A3 & B2 & C3 & D2 & E2 & $\mathrm{F} 2$ & G3 & H3 & $\mathrm{I} 2$ & $\mathrm{~J} 2$ \\
\hline $81.16-604$ & A4 & B1 & $\mathrm{C} 1$ & D1 & E1 & $\mathrm{F} 4$ & G1 & $\mathrm{H} 2$ & $\mathrm{I} 3$ & $\mathrm{~J} 1$ \\
\hline $83.25-2$ & $\mathrm{~A} 2$ & B2 & $\mathrm{C} 4$ & D3 & E4 & F5 & G4 & H5 & I1 & $\mathrm{J} 1$ \\
\hline $85.22-1$ & A4 & B2 & $\mathrm{C} 4$ & D2 & E3 & $\mathrm{F} 1$ & G4 & $\mathrm{H} 3$ & $\mathrm{I} 3$ & $\mathrm{~J} 3$ \\
\hline Capitola & A2 & B2 & $\mathrm{C} 2$ & D2 & E2 & $\mathrm{F} 2$ & G2 & $\mathrm{H} 2$ & $\mathrm{I} 2$ & $\mathrm{~J} 2$ \\
\hline Chandler & A1 & B1 & $\mathrm{C} 1$ & D1 & E1 & $\mathrm{F} 1$ & G1 & H1 & I1 & $\mathrm{J} 1$ \\
\hline Douglas & A5 & B1 & $\mathrm{C} 1$ & D1 & E3 & F3 & G4 & $\mathrm{H} 4$ & $\mathrm{I} 1$ & $\mathrm{~J} 1$ \\
\hline Seascape & A6 & B2 & $\mathrm{C} 4$ & D1 & E3 & F3 & G1 & H1 & I1 & $\mathrm{J} 1$ \\
\hline
\end{tabular}

and 7 of 10 of the primers, respectively. The coefficient of coancestry between offspring and parent is identical to that between pairs of full-sibs, and on average the likelihood of discriminating among such relatives is the same. Thus, the variation detected in our sample was sufficient to discern among the closest relatives likely to be encountered in most strawberry breeding programs.

Based on these studies, it is clear that amplification profiles from only a few different primers are necessary to distinguish strawberry cultivars and that numerous markers should be available for genetic studies. Randomly amplified polymorphic DNAs show particular promise as a tool in strawberry genetic studies, because high levels of diversity were observed in a relatively narrow breeding population. Further, the power of this technique to differentiate among close relatives suggests that its use should overcome the limitations cited using isoenzyme polymorphisms (Arulsekar et al, 1981; Bringhurst et al, 1981).

We have only just begun to evaluate the inheritance patterns in each amplification profile, but preliminary indications are that the majority of the individual bands within an amplification profile segregate as if controlled by a single diploid locus with one or two alleles, even though the commercial strawberry is an octoploid. Resolution of the inheritance of the markers will facilitate statistical models that can infer parent genotypes; with a large number of segregating markers even more distant relationships could be resolved. These models can then be used to select germplasm in breeding programs.

\section{Literature Cited}

Arulsekar, S., R.S. Bringhurst, and V. Voth. 1981. Inheritance of PGI phosphoglucoisomerase and LAP leucine aminopeptidase isozymes in octoploid cultivated strawberry. J. Amer. Soc. Hort. Sci. 106:679-683. Bringhurst, S.R., S. Arulsekar, J.F. Hancock, and V. Voth. 1981. Electro- phoretic characterization of strawberry cultivars. J. Amer. Soc. Hort. Sci. 106:684-687.

Davis, T. 1993. A RAPD based map of diploid strawberries. Second Intl. Strawbery Symp., Baltimore, Sept. 1992.(Abstr.)

Grattapaglia, D., J. Chaparro, P. Wilcox, S. McCord, D. Werner, H. Amerson., S. McKeand, F. Bridgewater, R. Whetten, D. O'Mally, and R. Sederoff. 1992. Mapping in woody plants with RAPD markers: Application to breeding in forestry and horticulture, p. 37-40. In: Applications of RAPD technology to plant breeding. Joint Plant Breeding Symp. Ser., Minneapolis.

Haghighi, K. and J.F. Hancock. 1992. DNA restriction fragment length variability in the genomes of highbush blueberry. HortScience 27:4447.

$\mathrm{Hu}$, J. and C.F Quiros. 1991. Identification of broccoli and cauliflower cultivars with RAPD markers. Plant Cell Rpts. 10:505-511.

Klein-Lankhorst, R.M., A. Vermunt, R. Weide, T. Liharska and P. Zabel. 1991. Isolation of molecular markers for tomato (L. esculentum) using random amplified polymorphic DNA (RAPD). Theoretical Applied Genet. 83:108-114.

O’Brien, S.J. (ed.). 1990. Genetic maps. Cold Spring Harbor Press, Cold Spring Harbor, N.Y.

Paran, I., R. Kesseli, and R. Michelmore. 1992. Identification of restriction fragment length polymorphism and random amplified polymorphic DNA markers linked to downy mildew resistance in lettuce using near-isogenic lines. Genome 1021-1027.

SAS Institute. 1988. SAS/STAT user's guide. release 6.03. SAS Institute, Cary, N.C.

Vierling, R.A. and H.T. Nguyen. 1992. Use of RAPD markers to determine the genetic diversity of diploid wheat genotypes. Theoretical Applied Genet. 84:835-838.

Weeden, N.F., G.M. Timmerman., M. Hemmat, B.E. Kneen, and M.A. Lodhi. 1992. Inheritance and reliability of RAPD markers, p 12-17. In: Applications of RAPD technology to plant breeding, Joint Plant Breeding. Symposia Series, Minneapolis.

Williams, J.G.K., A.R. Kubelik, K.J. Livak, J.A. Rafalski, and S.V Tingey. 1990. DNA polymorphisms amplified by arbitrary primers are useful as genetic markers. Nucleic Acids Res. 18:6531-6535. 